\title{
MÍDIA, POLÍTICA E PESQUISAS DE OPINIÃO PÚBLICA
}

Fernanda Barth

\begin{abstract}
Resumo
Este artigo propõe uma reflexão sobre a centralidade da mídia na política com ênfase nos processos eleitorais. Para isto investigamos como os mecanismos cognitivos operam na construção da identidade, do saber político dos indivíduos e, por conseqüência, das suas escolhas eleitorais. Priorizamos a análise bibliográfica contextualizada dos autores nacionais relacionados aos temas, entre eles Lima (2004, 2006), Aldé (1996, 2001), Veiga (1998, 2002), Guazina (2004), Jorge (1997), Fontoura (2002) e Dias (1996). A conclusão é de que hoje é impossível pensar a esfera política fora das relações e influências dos mídia. Portanto, a centralidade da mídia em todos os processos políticos afeta desde a escolha dos candidatos, a construção da campanha e da estratégia de marketing até o resultado dos pleitos.
\end{abstract}

Palavras Chave: Mídia; Política; Opinião pública; Cognição; Campanha política.

\begin{abstract}
This article examines the role of the media in the politics with emphasis in the political arena with emphasis in the electoral process. We investigate how cognition mechanisms work in the construction of the political identification, in the political knowledge of the individuals and, consequently, in their voting behavior. We emphasize the analyses of a the literature composed of brazilian authors among them: Lima (2004, 2006), Aldé (1996, 2001), Veiga (1998, 2002), Guazina (2004), Jorge (1997), Fontoura (2002) e Dias (1996). The conclusion is that today study shows that presently is impossible to think the political sphere outside of the influence of the media. The central role of the media affects all the political processes since the selection of who is the better candidate, the strategy of the political campaign until the elections results.
\end{abstract}

Key-Words: Media; Politics; Public opinion; Cognition; Political campaign.

\section{A centralidade da mídia- enquadramentos, quadros de referência e chaves explicativas}

A mídia não é apenas portadora de informação, seu papel central na sociedade como formadora de opinião pública a tornou também central na construção da imagem que as pessoas fazem da política. Os enquadramentos dados pela mídia, a forma como a informação é selecionada e editada, ou até suprimida, é a única ponte entre milhares de eleitores e a esfera política.

Nessa perspectiva, para Aldé, os enquadramentos podem ser descritos como: 
definições da situação construídas de acordo com os princípios de organização que governam os eventos- ao menos os eventos sociais- e nosso envolvimento subjetivo com eles. Estas estruturas cognitivas, que organizam o pensamento, são compostas de crenças, atitudes, valores e preferências, bem como de regras a respeito de como ligar diferentes idéias. São esquemas que dirigem a atenção para a informação relevante, guiam sua interpretação e avaliação, fornecem inferências quando a informação é falha ou ambígua, e facilitam sua retenção. Trata-se, portanto, de construções culturais que se realizam na narrativa, na articulação (ALDÉ, 2001, p.1).

Dois fatores são apontados pela autora como sendo essenciais na incorporação de um enquadramento por parte do indivíduo: a repetição de um enquadramento e sua generalidade. Quanto à generalidade: a construção cognitiva da realidade pode se dar em determinados níveis, dependendo da generalidade do esquema, da possibilidade da explicação dada servir para enquadrar novas informações. Quanto à repetição, Aldé argumenta que "a insistência em determinados enquadramentos por parte da mídia encontra respaldo, no receptor, na tendência a incorporar reiterações e no uso rotineiro de mecanismos cognitivos consoantes com as características discursivas dos enquadramentos oferecidos pelas emissoras" (ALDÉ, 2001, p.3).

Isso significa que se temos um grupo que detém um monopólio envolvendo rádio, TV e Jornal, e se este grupo tiver interesse em vender determinado enquadramento como realidade, constituindo os "cenários de representação da política" (LIMA, 2004), basta que divulgue por todos os seus meios, tantas vezes quanto possível, mensagens afins, e exemplos ilustrativos que vendam o mesmo argumento. Assim pode-se criar um ambiente favorável na opinião pública para que esta incorpore o enquadramento dentro de seu referencial simbólico e na construção da sua maneira de ver o mundo.

As notícias podem ser usadas na construção de explicações permanentes sobre o mundo político. Os meios de comunicação integram a memória semântica "que serve para atribuir significados a um mundo complexo, sem sobrecarregar intelectualmente o indivíduo com a necessidade de comprovação, evidência e demonstração do 
processo de julgamento" (ALDÉ e DIAS, 1998, p.3). Para Porto (1999), os meios de comunicação de massa não são condutores neutros de informação, mas instituições que dão significado e interpretam eventos e temas políticos.

Em relação à penetração de uma mensagem no público, Aldé (1998) explica que existem três mecanismos cognitivos que colaboram para que a mensagem que é passada pela mídia seja facilmente aceita e incorporada:

a) a predileção dos indivíduos por discursos que apresentam uma posição, privilegiando o pré-processamento e enquadramento dos eventos pelos meios- a essência dos fatos;

b) o caráter documental que os telespectadores atribuem ao que vêem- o estatuto visual da verdade;

c) a personalização dos fatos e eventos políticos, fazendo com que os receptores organizem o mundo mais em termos de seus personagens do que em termos institucionais ou históricos- $a$ novelização.

Portanto, se é nos próprios meios que se constroem as representações dos sujeitos sobre política, a mídia torna-se a própria arena de constituição e negociação da legitimidade política. Para a autora, é preciso aprofundar a investigação de como os grupos sociais e instituições podem criar distorções no processo democrático através do controle de atalhos ou construção de enquadramentos influindo na construção dos referenciais políticos dos cidadãos.

A televisão, por ser um veículo de massas e pela própria estruturação da mensagem e suas implicações na cognição dos indivíduos, e a imprensa escrita influenciam na elaboração da agenda pública e na construção dos cenários de representação da política, o CRP. Cenários que, por sua vez, agem diretamente sobre candidatos e eleitores. A este respeito, Lima (2006) apresenta sete teses entre mídia e política listadas a seguir:

1.A mídia ocupa papel central nas sociedades, em particular na esfera política;

2.Não há política nacional sem mídia; 
3.A mídia está exercendo várias funções tradicionais dos partidos políticos;

4.A mídia alternou radicalmente as campanhas eleitorais;

5.A mídia se transformou, ela própria, em importante ator político;

6.As conseqüências históricas específicas do sistema de mídia no Brasil potencializaram o seu poder no processo político;

7.As características específicas da população brasileira potencializam o poder da mídia no processo político, sobretudo no processo eleitoral.

Aldé (2001), por sua vez, descreve como operam as chaves de compreensão do mundo e os quadros de referência na construção da opinião do cidadão comum sobre a política. A autora assevera que o cidadão comum, obrigado a votar, recorre aos atalhos ${ }^{1}$ fornecidos pela mídia para justificar suas opiniões políticas perante os outros e construir sua própria visão de política, minimizando o custo de tal ação sem se sobrecarregar intelectualmente com a necessidade de comprovação ou evidência. A visão do cidadão comum sobre política é midiatizada e fortemente influenciada pelos cenários de representação da política e pelos enquadramentos dados pela mídia a determinados assuntos políticos, candidatos e partidos. Na maioria das vezes, a televisão assume o papel de repertório primário de exemplos fornecendo explicações prontas. Isto sintetiza a centralidade da mídia no comportamento eleitoral. Para consubstanciar este ponto de vista Aldé argumenta que:

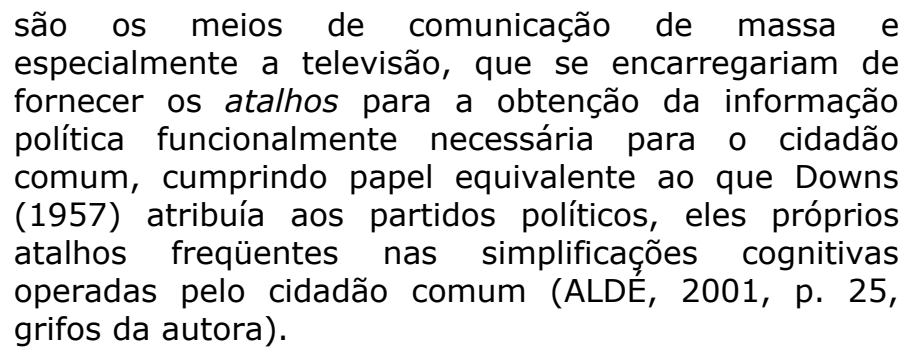

Na mesma linha de análise, Guazina (2007, p. 53) procura estabelecer as relações entre mídia e política. Segundo a autora, "Os

1 "A idéia de que as pessoas operam cognitivamente recorrendo a repertórios relativamente constantes de exemplos ajuda a entender por que a tendência é incorporar aos esquemas explicativos apenas a conclusão ou a moral de uma seqüência de fatos, descartando os detalhes" (Aldé, 2001, p. 25). 
meios de comunicação deixaram de ser entendidos como canais e passaram a ser vistos como potenciais construtores de conhecimento, responsáveis pelo agendamento de temas públicos e formadores de compreensão sobre mundo e política".

Em relação à influência da mídia, Pinto (1995) defende que o discurso político não tem mais um local privilegiado de enunciação. Sua construção se dá em um espaço menos definido, abrangendo tanto os partidos, governo, legislativo, quanto os meios de comunicação. $\mathrm{Na}$ análise que faz do discurso de campanha presidencial de 1994, no embate Lula X Fernando Henrique Cardoso (FHC), Pinto questiona até que ponto o discurso jornalístico redefine o discurso político. A autora acredita que existe uma correlação direta entre opinião jornalística e o encaminhamento de uma campanha política.

Por sua vez, Vladimyr Jorge (1997, p. 128), parte do pressuposto de que as pessoas são sempre influenciadas pelos meios de comunicação em uma eleição e que o fato de que "por trás de cada jornal ou aparelho de TV e de rádio há um grupo de pessoas controlando tais meios e que essas pessoas, como qualquer outra parcela da sociedade tem suas opiniões e interesses próprios" nos coloca um grande problema: como evitar que em uma sociedade pluralista apenas um ponto de vista vigore, "no momento em que os cidadãos estão formando opinião acerca dos candidatos e dos partidos e pensando, a partir desta opinião, em quem irão votar".

Para Fontoura (2002), o papel fundamental que a mídia exerce na criação da imagem do candidato é inegável:

$$
\begin{aligned}
& \text { a posição assumida por candidatos no decurso de um } \\
& \text { processo eleitoral e o modo como informações e } \\
& \text { notícias são transmitidas ou veiculadas na e pela } \\
& \text { imprensa permitem a construção de Cenários de } \\
& \text { Representação Política que podem ou não ser } \\
& \text { adequados a determinados partidos e candidatos } \\
& \text { (FONTOURA, 2002, p. 14-15, grifos da autora). }
\end{aligned}
$$

Nesse sentido, Fontoura cita a importância da mídia e dos cenários de representação aí construídos identificando-a como objeto 
fundamental de análise para a compreensão do poder político no mundo contemporâneo.

\title{
Cenários de representação da política
}

O conceito de cenários de representação da política foi desenvolvido por Lima (2004), um dos estudiosos brasileiros que mais tem se dedicado à área da economia da comunicação e à investigação dos efeitos da mídia sobre a política e os eleitores. A definição de CR-P passa pelo entendimento de como se estruturam os imaginários sociais (representação global e totalizante da sociedade) e de como os meios de comunicação de massa fabricam e emitem os imaginários sociais. A partir daí, pela compreensão de como funciona o conceito de hegemonia e contra-hegemonia de Gramsci, podemos entender como operam, principalmente via mídia, os elementos discursivos na disputa por espaço simbólico no imaginário social.

O conceito se desdobra em "cenário como espaço onde a ação se desenvolve" em "representação, significando não só representar a realidade, mas também constituí-la" (LIMA, 2004, p.181-182). Nesse plano, onde são constituídas significações, um cenário de representação

\begin{abstract}
é o espaço específico de representação da política nas democracias representativas contemporâneas, constituído e constituidor, lugar e objeto da articulação hegemônica total, construído em processos de longo prazo, na mídia e pela mídia, sobretudo na televisão. Como a hegemonia, O CR-P não pode nunca ser singular. Temos, portanto de acrescentar o conceito de contra CR-P ou de CR-P alternativo (LIMA, 2004, p.182183 , grifos do autor).
\end{abstract}

Lima (2004, p.187) sustenta que o CR-P, construído na e pela mídia, define e delimita o próprio espaço da realidade política no mundo contemporâneo. Os três pressupostos básicos para o conceito são: 1) a existência de uma sociedade mídia-centered; 2) o exercício de uma hegemonia; 3) a existência da televisão como medium dominante.

$\mathrm{Na}$ análise desses pressupostos, Lima argumenta que os meios de comunicação eletrônicos transformaram a mídia no aparelho privado de hegemonia mais eficaz na articulação hegemônica, sendo capaz de 
construir e definir limites da realidade dentro dos quais ocorre a disputa política. Dificilmente um candidato vencerá as eleições se não ajustar sua imagem pública ao CR-P dominante, ou construir um CR-P contrahegemônico eficiente. Por isso é tão importante questionar "qual o papel no processo político dos que controlam a emissão de mensagens na mídia?" (LIMA, 2004, p. 210). Ao que se acrescentaria a importância de também questionar como se dá a interação entre a mídia e os receptores de suas mensagens. Quanto aos receptores da mídia, Lippmann (1922), no início do século XX, se referia a um pseudoenvironment e que pode ser considerado atual, apesar de anterior ao surgimento da TV. Como se lê no texto: "O que cada pessoa faz não é baseado em conhecimento direto e seguro mas em imagens feitas por ela e dadas a ela [...] O modo pelo qual o mundo é imaginado determina o que as pessoas irão fazer em cada momento particular". Avaliações dessa natureza nos sugerem buscar o entendimento de como esta conexão (recepção/imagem) tem sido tratada pela literatura pertinente.

\section{Cognição, agenda setting e opinião pública}

Os efeitos da ação mediadora dos mecanismos de comunicação sobre a opinião pública e a conduta política das pessoas têm estimulado um debate bastante intenso. Saperas (1987), por exemplo, conceitua efeito cognitivo como o conjunto das conseqüências que derivam da ação mediadora dos meios sobre os conhecimentos partilhados por uma comunidade. $\mathrm{O}$ autor acredita que o efeito dos meios de comunicação de massa extrapola a simples persuasão e chega à conclusão de que a forma como os meios comunicam altera a própria percepção da realidade por parte da audiência, mesmo que indiretamente. Saperas aponta para a importância dos efeitos cumulativos na formação da opinião pública. Para o autor, em relação ao campo político, a influência da mídia é central como distribuidora de conhecimentos sobre o meio, sobre as propostas dos candidatos e sobre o próprio comportamento eleitoral. 
O estudo seminal de Lazarsfeld et all, The people's choice (1944), introduz o conceito de recepção seletiva da mensagem por parte dos eleitores expostos à propaganda política, o que significaria que os eleitores não seriam influenciados apenas pelas mensagens veiculadas na campanha, mas por conceitos sócio-culturais previamente estabelecidos. Saperas (1987) refuta parcialmente esta capacidade seletiva da audiência. Considera que a teoria dos autores de que a comunicação política é capaz de vender apenas as mensagens que não impliquem em conflito para os eleitores, operando somente no âmbito de reforço das atitudes prévias não é uma lei, é apenas uma variável. Noelle-Neumann (1993) também refuta a teoria da capacidade seletiva da audiência. Nessa perspectiva, Saperas (1987) enumera algumas considerações dessa situação:

a)a existência de uma hierarquia de valores pode abolir facilmente a percepção seletiva;

b)em numerosas situações o conhecimento das comunicações discordantes ou indesejáveis é sentido como útil;

c)a percepção seletiva é mais viável na imprensa do que na televisão pela própria forma com que comunica o conteúdo;

d)existe toda uma geração já desenvolvida após o advento da TV cuja percepção da comunicação é fortemente influenciada pela comunicação televisiva e portanto condicionada por ela;

e)a compreensão da informação passada pela televisão demanda menos esforço e sua insolvência reduz a capacidade seletiva da audiência.

O que de fato ocorre em relação a teorias como a da capacidade seletiva da audiência é que, além dos meios de comunicação de massa terem evoluído muito com o advento da TV de grande audiência, ela foi elaborada em 1940, em outro contexto. Saperas (1987) assinala que é impossível estudar qualquer processo comunicacional descontextualizado. O processo comunicacional não é estático, mas dinâmico e mutável. O autor argumenta que podemos estabelecer três tipos de efeitos cognitivos relativos à comunicação de massas:

$1^{0}$ - efeitos resultantes da capacidade simbólica de estruturar a opinião pública:

REVISTA DEBATES, Porto Alegre, v.1, n.1, p. 26-48, jul.-dez. 2007. 
[...] podemos afirmar que os mídia, como comunicação pública, determinam as formas de orientação da atenção pública, a agenda de temas dominantes que reclamam essa atenção e sua posterior discussão pública, a hierarquização da relevância destes temas e a capacidade de discriminação temática que os indivíduos manifestam [...].

20- efeitos resultantes da distribuição social dos conhecimentos coletivos:

Nesta divisão incluem-se os efeitos cognitivos que resultam da distribuição social dos conhecimentos em função dos diferentes setores sócio-econômicos, culturais ou profissionais [...].

$3^{0}$ - efeitos relativos às notícias como forma de construção da realidade social:

Nesta terceira divisão inclui-se o conjunto dos efeitos cognitivos relativos às notícias que, como produto de uma determinada instituição social, determinam uma construção social da realidade [...] (SAPERAS, 1987, p. 49-50).

Em relação aos efeitos resultantes da capacidade simbólica dos meios de comunicação de massas para estruturarem a opinião pública, o estudo da agenda setting ${ }^{2}$ parte da constatação do poder que os meios de comunicação de massas exercem para "influenciar e determinar o grau de atenção que o público dedica a determinados temas expostos à atenção e ao interesse coletivos" (SAPERAS, 1987, p.54). A agendasetting influencia não só o campo político como todas as esferas da sociedade, seja cultura, esportes ou moda.

$\mathrm{O}$ autor parte do pressuposto de que a agenda dos meios de comunicação de massa é a base para a agenda pública e a relação que se estabelece entre as duas é proporcional à ênfase dada pela mídia ao tratamento de determinados temas. Não é questão de determinar o que as pessoas pensam, mas aquilo sobre o que pensam, e esta é a função do gatekeeper que segue a "linha editorial" (SAPERAS, 1987, p.56) do meio de comunicação. Saber determinar como age o gatekeeper, como ele seleciona a informação que vai ou não ser noticiada deve ser motivo para estudos futuros, visto que eles são os juízes do que será informado e da forma como será. Dito isso, vejamos agora alguns aspectos da

${ }^{2} \mathrm{O}$ estudo do agenda setting foi introduzido por Mc Combs e Shaw no artigo The agendasetting function of mass media (1972). 
relação entre marketing político e democracia, para então enfocarmos a questão do voto útil e das eleições de 2004 em Porto Alegre.

\section{Marketing político e democracia de público}

No que se refere ao marketing político, é relevante tecer algumas considerações a respeito das origens de sua versão moderna, baseada na imagem, na emotividade e nas pesquisas de opinião. Seu surgimento é localizado pela bibliografia pertinente nos Estados Unidos, em 1964, na campanha de Lyndon Johnson para a presidência. Nesta Campanha foi veiculado o primeiro spot $^{3}$, que revolucionou a propaganda política na TV e, conseqüentemente, o marketing. Este também é o momento em que a mídia televisiva passa a ter uma importância crucial nos processos eleitorais, influenciando, inclusive, a mudança do perfil e da imagem dos candidatos a cargos políticos e a especialização das equipes de marketing e estratégia.

Segundo Laurence Rees (1995), na sua análise das eleições norte-americanas, Tony Schwartz, contratado para a campanha de Johnson, não queria alterar as idéias dos eleitores, apenas buscava reforçar as emoções que o eleitor já tinha. As pesquisas detectaram que a população temia que o candidato Barry Goldwater usasse a bomba nuclear se eleito. Schwartz fixou-se neste pensamento extremo e trabalhou em um comercial que ameaçava a América com a bomba ${ }^{4}$. Goldwater perdeu as eleições por uma diferença recorde: $61,3 \%$ para Lyndon Johnson; 38,7\% para Goldwater.

O espectador não é passivo neste processo de comunicação. Por uma questão de audiência ele é a fonte primeira da mensagem que, captada das massas em estado bruto, como desejos, anseios, demandas, é trabalhada pela mídia e reenviada para as massas. Bem

\footnotetext{
${ }^{3}$ Propaganda política com duração de comercial de TV que passa inserida na programação diária das emissoras durante o Horário de Propaganda Eleitoral Gratuito (HPEG).

${ }^{4} \mathrm{O}$ comercial de 30 segundos era intitulado $A$ menina e o malmequer e mostrava uma menina desfolhando uma flor, pétala por pétala, enquanto se sobrepõe uma contagem regressiva que acaba em um lento zoom no olho da menina e na explosão da bomba atômica. Entra uma locução dramática: "O que está em jogo é um mundo onde possam viver os filhos de Deus ou as trevas. Ou nos amamos ou morremos. Vote no Presidente Johnson em 3 de novembro. O que está em jogo é muito importante para que você fique em casa".
} 
como a propaganda de um modo geral, e, principalmente, a propaganda política. Não é possível vender uma inverdade completa, é preciso que a mensagem enviada já esteja, de alguma forma, no inconsciente do eleitor, como uma crença, uma dúvida, uma intuição. A propaganda só faz trazê-la à tona, fortalecendo-a e cristalizando-a.

As técnicas de comunicação do marketing político são ainda mais eficientes se a mensagem for passada nos spots, dentro da programação normal das emissoras. Os spots foram introduzidos na propaganda política brasileira em 1996 e sua vantagem é que pega os eleitores desprevenidos. Alessandra Aldé e Heloísa Dias (1998) citam um estudo feito nos Estados Unidos que revelou que os spots são mais lembrados e têm maior importância na definição de voto do que os debates entre candidatos.

Na era da mídia eletrônica. o candidato e a equipe por trás dele passam a ter que controlar a campanha passo a passo através de pesquisas qualitativas para saber se a imagem do candidato está sendo percebida da forma que se quer. Quem quer se eleger está refém destas técnicas que envolvem o entendimento e o domínio da psicologia do eleitor, da comunicação e das corretas análises de conjuntura. É preciso ter o feeling das expectativas dominantes e a capacidade de encarná-las em seu discurso e em sua imagem com autenticidade. Vive-se, nesse cenário, o que Bernard Manin (1995) chama de Democracia de Público, ou seja, uma democracia marcada por partidos enfraquecidos, por um forte personalismo, por uma grande importância dada pela mídia às pesquisas de opinião, pela transformação dos políticos em comunicadores e pelo crescimento do eleitor flutuante. 
Apesar de Manin $^{5}$ ter construído sua teoria da Democracia de Público em um outro contexto, em um sistema partidário diferente do brasileiro, no básico opera da mesma forma. A influência que o público tem nas pesquisas, que por sua vez determinam o discurso do candidato, é atual e opera aqui. Salvo raras exceções, os partidos políticos brasileiros são fracos em termos de identificação programática e ideológica. O personalismo no Brasil tem aumentado a cada eleição. A mídia brasileira exerce uma enorme influência nos cenários de representação da política como podemos ver nos trabalhos de Lima (2004, 2006) e na construção da forma como o eleitor vê o mundo e a política, como se constata no estudo de Aldé, A construção da política cidadão comum, mídia e atitude política (2001). As pesquisas de opinião estão cada vez mais presentes na mídia e dentro do horário eleitoral gratuito.

\section{Pesquisas estimuladas de intenção de voto e simulação de segundo turno}

As pesquisas de opinião, como observa Baquero (1995), são o complemento de um processo político maior e que não podemos atribuir, sem maiores reflexões, uma influência desproporcional das pesquisas na estruturação da opinião dos cidadãos sob o risco de negligenciarmos "ideologia subjacente à construção política do país" ( $p$. 91).

Conforme Baquero (1995) argumenta, para determinar os possíveis efeitos deletérios ou manipulativos que as pesquisas possam

5 É preciso salientar, porém, uma questão problemática em relação à aplicação da Democracia de Público de Manin no Brasil. O autor lista uma série de características importantes que devem estar presentes na democracia. Uma delas é a liberdade de opinião pública. Manin coloca que os meios de comunicação modernos devem ter neutralidade política, ou seja, serem apartidários. Cita também o importante caráter nãopartidário dos institutos de pesquisa, que tanto influenciam o comportamento das campanhas, candidatos e eleitores. Só que no Brasil, como coloca Aldé (2001, p.17) "mais da metade das emissoras de rádio e televisão pertencem a políticos, parentes de políticos ou pessoas ligadas a eles". As grandes revistas de circulação nacional estão nas mãos de grupos de interesse e exercendo pressão política. Outro importante aspecto é o dinheiro que sai dos cofres públicos para pagar publicidade institucional do governo. Publicidade responsável por uma significante parcela dos lucros dos meios de comunicação de massa. A isenção e a imparcialidade ficam em risco neste sistema. Por isso, apesar de muitas das características da democracia de público estarem presentes no nosso contexto, ela sofre uma subversão. 
ter sobre os eleitores, deve-se dar especial atenção para a forma como estes resultados são divulgados e apresentados. Devemos nos perguntar quem apresenta estas informações e qual o interesse dessas pessoas ou organizações no processo eleitoral. De fato, além disso, a forma como as pesquisas são apresentadas e divulgadas pelos meios de comunicação pode determinar o impacto que elas terão no eleitorado.

O uso que se faz de e a maneira como é divulgada a pesquisa eleitoral já encontrou críticas e observações contundentes nas últimas eleições. Em artigo intitulado Pesquisismo, publicado no jornal Folha de São Paulo em 18/10/1994, o tucano José Serra afirmou que o fato dos meios de comunicação transformarem a divulgação das pesquisas no item principal de suas pautas de campanha

\begin{abstract}
estimula a que o eleitor caia na armadilha de substituir seu direito de informar-se sobre os candidatos e seu dever de avaliá-los, por uma espécie de jogo de adivinhação para descobrir o candidato que tende a ganhar e que, simplesmente por isso, receberia seu voto. Tal uso distorcido das pesquisas desvirtua 0 processo eleitoral.
\end{abstract}

Barretto (1997), em estudo sobre as pesquisas de opinião pública no processo eleitoral brasileiro, cita Jânio de Freitas, em 1994, na Folha de São Paulo a respeito dos não cidadãos. Diz ele:

\begin{abstract}
de oito candidatos a presidente, a disputa eleitoral esteve sempre a dois. Para isso contribuíram muito a indução feita pelas pesquisas, cujo papel nas eleições precisa passar por um questionamento sério, e a marginalização de seis candidatos pelos meios de comunicação, que só lhes dedicaram as atenções ociosas para guardar as aparências mínimas de igual tratamento (FREITAS apud BARRETO, 1997, p. 54).
\end{abstract}

Barretto (1997) é um crítico do modo como as pesquisas são divulgadas na mídia, considerando a forma e a intensidade com que são divulgadas ferramentas para a manipulação do eleitorado. Para o autor, os mídia ${ }^{6}$ revestem as pesquisas eleitorais com um aparente invólucro de coisa certa e definitiva, fazendo o eleitor pensar que seu resultado é fator inalterável. Da repetição de uma seqüência de pesquisas que apontam a mesma tendência pode vir a influência sobre o eleitorado que

${ }^{6}$ Meios de comunicação de massa e profissionais da comunicação. 
Barretto (1997) chama de maria-vai-com-as-outras. Esta repetição descrita por Barreto se encaixa nos estudos de Aldé (1998) sobre o aumento da penetração da mensagem no público pelo nível de repetição dos enquadramentos.

Barreto cita também trecho de artigo Políticos distorcem pesquisas de opinião, publicado por Mário Augusto Jakobskind, no Jornal Bahia hoje, em 1996, onde o autor coloca que as pesquisas influenciaram no eleitorado no sentido de

\begin{abstract}
induzir o eleitor a se posicionar, segundo a lógica de que geralmente quem vai às urnas prefere seguir a tendência apontada. Grosso modo é o mesmo raciocínio dos torcedores de futebol. É muito mais fácil alguém se posicionar, digamos, por um vitorioso e forte Flamengo do que um derrotado clube pequeno (JAKOBSKIND apud BARRETO, 1997, p. 57).
\end{abstract}

A questão básica de como os meios de comunicação tratam a divulgação das pesquisas é relevante no sentido de que pode prevalecer, no caso da TV, o estatuto visual da verdade detectado por Aldé (1998) ou ainda, na intenção de influenciar um CR-P para privilegiar um candidato, como vimos em Lima (2004). Outro fator é de que as pesquisas não são uma realidade solidificada, mas são o retrato de um momento específico, dentro de um contexto pontual. Imaginemos que determinada pesquisa é realizada justamente quando um candidato ou partido $\mathrm{X}$ acabou de tomar certa medida impopular ou que naquele dia o noticiário divulgou alguma coisa positiva sobre ele. O resultado da pesquisa pode ser a repercussão daquele momento, quando na semana seguinte, os fatos já se diluíram e o que influiu já não conta mais. Se nova pesquisa fosse realizada, traria resultados diferentes. Neste caso, o problema também é que os meios de comunicação costumam desprezar os elevados percentuais de indecisos e interpretam o resultado das pesquisas exclusivamente baseados nos baixos índices de eleitores que já se definiram. Quanto mais cedo começar o processo de divulgação das pesquisas, maior a propensão daqueles dois candidatos que largaram na frente se consolidarem como as melhores opções, mesmo que seus índices não sejam muito altos. 
Outra questão se refere ao fato de que muitas vezes os meios transformam em manchetes pequenas quedas ou subidas dos índices dos candidatos que estão dentro da margem de erro das pesquisas como se a margem de erro não existisse. As pesquisas eleitorais se tornaram um dos instrumentos mais eficazes de propaganda eleitoral. A divulgação de suas projeções é um dos mais importantes meios de se eleger ou derrotar um candidato. Segundo Lima (2004) foi nas eleições presidenciais de 1989, quando Collor se elegeu, que a divulgação das pesquisas de intenção de voto e suas simulações de segundo turno primeiro mostraram seu poder no Brasil.

No seu capítulo sobre Televisão e política: hipótese sobre o $1^{\circ}$ turno da eleição presidencial de 1989, Lima (2004) argumenta que existe um paralelo entre a subida vertiginosa de Collor nas pesquisas estimuladas de intenção de voto e a veiculação no rádio e na televisão dos programas políticos anuais dos três partidos da coligação ao qual o candidato pertencia. Sobre o primeiro programa do PRN, Partido da Reconstrução Nacional, observa-se que ele atingiu $81 \%$ de audiência segundo o instituto Vox Populi.

Mas como a mídia pode operar pró-ativamente na construção de um CR-P? Lima (2004) demonstra que a construção do CR-P no telejornalismo da Rede Globo teve pelo menos duas vertentes principais, a cobertura favorável a Collor e a divulgação de pesquisas com projeção de votação em relação aos prováveis adversários de Collor no segundo turno (o que chamamos de simulações de segundo turno) e a divulgação, ou omissão, dos resultados quinzenais/semanais das pesquisas no primeiro turno. Estas pesquisas

incluíam uma pergunta aos eleitores que projetava a disputa para o segundo turno e, como Collor não mais perdeu o primeiro lugar desde abril - sete meses antes de 15 de novembro - a questão era saber quem seria o seu adversário. Dito de outra forma, a pesquisa passou a se comportar como se um dos vencedores do primeiro turno já pudesse estar definido e a fixar na memória do eleitor o nome de Collor como sendo este vencedor (LIMA, 2004, p.238). 
Para o autor, a periodicidade das pesquisas publicadas pelo instituto Ibope teve oscilação. O comentário em São Paulo era quando Collor cai o Ibope não sai. O autor faz ainda referência sobre a pesquisa realizada pelo IPEP (Instituto de Pesquisa de Pernambuco) e pelo mestrado em Ciência Política da UFPE (Universidade Federal de Pernambuco). Esta pesquisa determinou que para $41,5 \%$ dos entrevistados as pesquisas exerciam muita ou alguma influência na sua decisão eleitoral e outros $43 \%$ consideram a pesquisa muito importante porque determina se o candidato tem boa chance de ganhar. A pesquisa eleitoral influi diretamente na decisão de $41,5 \%$ dos entrevistados.

Foi com base no estudo feito sobre o CR-P das eleições de 1989 que Lima chegou à conclusão da vitória antecipada de Collor. Defende que a forma sistemática (novamente a repetição) como as pesquisas estimuladas de intenção de voto foram divulgadas fixou Collor no CR-P como vencedor virtual e antecipado do 10 turno.

Veiga (1996) salienta que os eleitores indecisos, que retardam a sua tomada de decisão na expectativa de que algum novo evento os ajude a decidir em quem votar, são os mais vulneráveis às expectativas de vitória divulgadas pelas pesquisas (teoria da espiral do silêncio). A tendência destes eleitores é se alinharem ao lado do candidato mais forte e segundo Noelle-Neumann (1993) esta percepção é adquirida pelo eleitor através dos meios de comunicação e observando o cotidiano, como o número de bandeiras, adesivos, conversas com conhecidos. Os eleitores que têm um candidato com menos chances de ganhar caem crescentemente em silêncio e contribuem, assim, para a sua derrota.

Os indecisos são mais fortemente influenciados pela propaganda do vencedor. Segundo a pesquisa desenvolvida por Veiga (1996) sobre o comportamento dos eleitores fluminenses em 1994, os votantes selecionavam as mensagens de acordo com os seus interesses e conhecimentos prévios e partindo desta base, elaboravam narrativas a respeito dos candidatos. O HPEG serviu para "converter os indecisos e para preservar a intenção de voto original daqueles que possuíam uma inclinação partidária" (VEIGA, 1996, p.63). 


\section{Horário de propaganda eleitoral gratuito}

Sobre a influência específica do HPEG no comportamento eleitoral existem trabalhos significativos sendo feitos em nível nacional. Veiga (1998), no seu estudo sobre o Horário Eleitoral, explica como o eleitor médio ${ }^{7}$ processa os complexos discursos apresentados e, apesar da escassez de recursos cognitivos sobre o tema política, responde à democracia com seu voto. Segundo a autora, apesar da deficiência cognitiva, o eleitor comum é um sujeito ativo, com motivações sociais e políticas na recepção e no processamento dos discursos das campanhas eleitorais. A propaganda eleitoral teria um impacto indireto sobre a opinião do eleitor, cabendo ao programa a função de oferecer argumentos aos indivíduos para que participem e divulguem as mensagens veiculadas nos debates que se reproduzem no cotidiano:

embora os eleitores não acompanhem diariamente o Horário do TRE, eles podem ter sua postura sobre o voto influenciada pela propaganda veiculada na TV. [...] a reprodução, ou mesmo a tradução, de um discurso de campanha por um amigo ou parente pode facilitar o processo persuasivo (VEIGA, 1998, p. 8).

Ainda para Veiga (2002), os eleitores também buscam no HPEG informações que amenizem a angústia individual motivada pela incerteza sobre o voto e ainda argumentos que possam ser utilizados para justificar a sua postura sobre a eleição no seu grupo social.

Já Lourenço (2001), na sua análise sobre as eleições de 1998 ao Governo de São Paulo e à Presidência da República, aponta duas questões importantes. Em primeiro lugar, o autor sugere que é um engano pensar que ninguém assiste ao HPEG. Lourenço explica que existe uma audiência extraordinária da propaganda eleitoral na televisão. Em pesquisa realizada no Rio de Janeiro e em São Paulo, no período entre 1986 a 1994, o HPEG foi campeão de audiência em todos os pleitos majoritários e em todos os níveis, tanto municipais, quanto estaduais e federais. A média de audiência nos dois estados, somando 20 pleitos, foi de $52 \%$. A segunda constatação foi que em uma pesquisa

\footnotetext{
${ }^{7}$ A autora coloca que o mapa do Tribunal Superior Eleitoral de 1998, contexto em que o trabalho foi desenvolvido, revela um país quase analfabeto, com mais de 70 milhões de pessoas com escolaridade abaixo do $1^{\circ}$ grau completo.
} 
publicada pelo jornal Folha de São Paulo, em 18 de agosto de 1998, cerca de $60 \%$ dos entrevistados, que ainda estavam indecisos com relação ao seu voto, acreditavam na importância do HPEG televisivo na decisão do voto. A conclusão do trabalho é de que "a propaganda eleitoral televisiva tem sim um público e que este público reconhece o HPEG como sendo importante dentro da campanha, especialmente entre os eleitores indecisos" (LOURENÇO, 2001, p.7).

É possível mensurar o impacto do HPEG nos eleitores indecisos quando o seu número cai substancialmente entre a primeira pesquisa feita, já durante a campanha política mas antes do início do HPEG, e pesquisas que são realizadas depois que o Horário Político começa. Na conclusão do paper Lourenço salienta que "o HPEG motiva as escolhas do eleitor, agrega e cristaliza suas preferências" e que após o início do HPEG "ocorre uma intensificação acentuada do processo decisório, a ativação do eleitorado, expresso na diminuição do número de indecisos e aumento na intenção de votos das principais candidaturas" (LOURENÇO, 2001, p.7).

\section{Eleição para Governo do Estado do Rio Grande do Sul em 2002}

O trabalho de Biancamano (2003) mostra que, nas eleições para o governo do estado do Rio Grande do Sul em 2002, os gaúchos estavam suscetíveis a serem influenciados pela divulgação das pesquisas de simulação de segundo turno como pudemos ver na vitória de Rigotto sobre o projeto de reeleição petista.

Biancamano (2003) observa que o discurso VIPOLU ${ }^{8}$, criado para a campanha de Germano Rigotto, candidato do Partido do Movimento Democrático Brasileiro (PMDB) foi elaborado com base em uma pesquisa qualitativa realizada antes do início do HPEG e que determinou o público alvo e a linguagem que seria utilizada durante toda a campanha. As pesquisas tinham detectado que naquele momento os gaúchos estavam cansados da bipolarização direita $x$ esquerda encarnada pelos

\footnotetext{
${ }^{8}$ VIPOLU = Vibrante, Popular e Luminoso. O que significa que a direção geral da campanha não podia veicular em seus programas nada que não cumprisse os três requisitos.
} 
candidatos do Partido Popular Socialista (PPS), Antônio Britto ${ }^{9}$, e do Partido dos Trabalhadores (PT), Tarso Genro, e não queriam ver brigas ou críticas nos programas da campanha dentro do HPEG.

A campanha acertou o alvo. Rigotto que se mantinha em quarto lugar nas cinco primeiras pesquisas publicadas deu um salto na primeira pesquisa CEPA/UFRGS publicada após o início do HPEG, em 12 de setembro 2002, indo para o terceiro lugar. Outro fator importante nesta primeira pesquisa depois do início da campanha na TV foi que nas simulações de segundo turno Rigotto ganhava de Antônio Britto por quase 6 pontos. No dia 19 de setembro outra pesquisa CEPA/UFRGS é publicada e mostra que apesar de Rigotto ainda estar em terceiro lugar na estimulada, nas simulações de segundo turno ganharia de Britto e de Tarso. É a primeira pesquisa onde Rigotto se apresenta como candidato capaz de vencer o PT que buscava a reeleição ao governo do Estado. Biancamano mostra que desta pesquisa para a próxima, Rigotto cresce quase 5 pontos em uma semana e entra em empate técnico com Britto, em segundo lugar. A partir daí o que se vê é uma migração de votos de Britto para Rigotto, o que faz com que o candidato do PPS caia consideravelmente na pesquisa posterior da CEPA/UFRGS, publicada em 03 de outubro 2002, indo para o terceiro lugar, quase 13 pontos percentuais atrás de Rigotto.

O eleitorado estava procurando um candidato para vencer o PT, e, depois que constatou a viabilidade da campanha de Rigotto, preferiuno a Britto. As intenções de voto em Tarso Genro permanecem inalteradas do meio até o fim do primeiro turno, mantendo aproximadamente $34 \%$ por quatro pesquisas sucessivas do instituto CEPA/UFRGS em 12 de setembro de 2002, 19 de setembro de 2002, 26 de setembro de 2002 e 03 de outubro de 2002.

Ao final do primeiro turno Tarso faz $37,25 \%$ dos votos e Rigotto $41,17 \%$ dos votos, vencendo, posteriormente, a eleição para o Governo do Estado do Rio Grande do Sul. Na primeira pesquisa publicada no segundo turno, no dia 9 de outubro, Germano Rigotto tem $58,8 \%$ das

\footnotetext{
${ }^{9}$ É importante salientar que apesar de estar em um partido que tem a palavra Socialista no nome, PPS, o candidato Britto era usualmente associado à direita.
}

REVISTA DEBATES, Porto Alegre, v.1, n.1, p. 26-48, jul.-dez. 2007. 
intenções de voto e Tarso 35,8\%. Britto, que tinha começado a disputa em segundo lugar com $34,3 \%$ dos votos, conforme a pesquisa CEPA/UFRGS publicada em Zero Hora do dia 10 de maio de 2002, acaba o primeiro turno com apenas $12,31 \%$ dos votos. Os votos de Britto migraram para Rigotto após a divulgação de pesquisas de simulação de segundo turno que demonstravam que Rigotto venceria Tarso. Esta eleição nos indica, claramente, o caminho aberto para a apelação ao voto útil no Rio Grande do Sul.

Sobre a influência das pesquisas no resultado da eleição de Rigotto, Silva (2004) coloca que as pesquisas publicadas dentro dos programas de Rigotto no HPEG enfatizavam que o candidato do PMDB venceria qualquer um dos demais no segundo turno (simulação de segundo turno). O CR-P de vitória foi construído também com a veiculação de trechos de opiniões sobre o crescimento de Rigotto emitidas por colunistas políticos nos jornais. Na conclusão do trabalho de Silva sobre as eleições de 2002, a autora ressalta a importância da utilização das pesquisas dentro da elaboração dos CR-Ps:

Tal variação na construção da imagem de candidatos e partidos verificada durante o tempo de veiculação dos programas eleitorais dá margem para outra constatação: a de que as pesquisas de opinião, em determinadas ocasiões, tornaram-se elementos centrais nos ditames da elaboração dos programas do HPEG. Desta forma, afirma-se que os cenários de representação da política construídos pela mídia nas eleições de 2002 foram incorporados aos discursos dos programas eleitorais. A afirmação considera, em primeiro lugar, a mudança de tônica das mensagens ocorridas em conformidade com momentos diversos de divulgação de pesquisas, estabelecendo mudanças de rumo nos recursos utilizados na campanha pela TV. E, em segundo, as referências- positivas e negativasfeitas pelos programas a respeito das predições eleitorais e dos institutos de pesquisa envolvidos (SILVA, 2004, p. 97-98).

Silva (2004) também destaca que o universo jornalístico, ao interpretar, traduzir e dar visibilidade na divulgação das pesquisas, teve forte influência na composição do CR-P que permitiu a vitória de Rigotto. 


\section{Conclusão}

Analisar qualquer acontecimento ou posição política fora da influência da mídia é praticamente impossível. A centralidade da mídia em todos os processos políticos afeta desde a escolha dos candidatos para a disputa eleitoral, a construção da campanha e da estratégia de marketing, até o resultado dos pleitos.

A repetição de enquadramentos, da ênfase e da forma de divulgação das pesquisas de opinião, feita tanto pelos meios de comunicação como pelas campanhas políticas, age diretamente na formação da opinião pública, induzindo o comportamento eleitoral. Em relação às pesquisas de opinião parece-nos que o uso das simulações de segundo turno tem especial importância na indução do comportamento eleitoral e na formação dos cenários de representação da política.

A relação entre mídia e política tem sido estudada cada vez mais pelas ciências sociais brasileiras na intenção de determinar e entender as características da relação, seus prós e contras para o amadurecimento e a melhoria do sistema democrático. Consideramos esta investigação extremamente relevante principalmente porque acreditamos que trazendo o assunto ao debate, estaremos disponibilizando as bases para que outros trabalhos sejam constituídos, talvez traçando um norte para que os nossos legisladores e juristas possam corrigir eventuais distorções e abusos que podem ocorrer na relação entre mídia e política.

Fernanda Barth é bacharel em Comunicação pela Pontifícia Universidade Católica, Mestre em Ciência Política pela Universidade Federal do Rio Grande do Sul e assessora de Comunicação Política do Vice-governador do Rio Grande do Sul.

E-mail: fernandabarth@hotmail.com. 


\section{Referências:}

ALDÉ, A. A construção da política - Cidadão comum, mídia e atitude política. 2001. 254 f. Tese (Doutorado em Ciência Política)- IUPERJ, [2001].

ALDÉ, A.; DIAS, H. Intervalo surpresa: spots eleitorais na campanha municipal de 1996. Comunicação e Política, Rio de Janeiro, v.5, n.1, p. 83-100, jan.-abr. 1998.

BAQUERO, M. Opinião pública e pesquisas eleitorais. In: BAQUERO, M. (Org.). Brasil - transição, eleições e opinião pública. Porto Alegre: Editora da Universidade/UFRGS, 1995. p. 79-92.

BARRETTO, L. As pesquisas de opinião pública no processo eleitoral brasileiro. Rio de Janeiro: Editora Lumen Juris, 1997.

BIANCAMANO, P. da R. O marketing político nas eleições para governador do Estado do Rio Grande do Sul em 2002: o caso do candidato Germano Rigotto. 2003. 95 f. Monografia (Graduação em Administração), UFRGS, [2003].

FONTOURA, M. C. de. Cenários de representação: mídia e política nas eleições municipais em Porto Alegre (2000). 2002. 115 f. Dissertação (Mestrado em Ciência Política)- Instituto de Filosofia e Ciências Humanas, UFRGS, [2002].

GUAZINA, L. O conceito de mídia na comunicação e na ciência política: desafios interdisciplinares. Revista Debates, v. 1, n. 1, p. 49-54, jul.dez. 2007.

JORGE, V. L. Os meios de comunicação de massa nas campanhas eleitorais. Comunicação \& Política, Rio de Janeiro, v. 4, n. 1, p. 126-133, 1997.

LAZARSFELD, P. et al. The people's Choice. New York: Duel, Sloan and Pearce, 1944.

LIMA, V. de. Mídia: teoria e política. 2 ed. São Paulo: Fundação Perseu Abramo, 2004.

- Mídia: Crise Política e Poder no Brasil. São Paulo: Fundação Perseu Abramo, 2006.

LIPPMANN, W. Public Opinion. New York: Mac Millan, 1922.

LOURENÇO, L. C. HPEG e intenção de voto - observações sobre as eleições de 1998 ao Governo de São Paulo e a Presidência da República. Paper apresentado no XI Congresso dos Sociólogos do Estado de São Paulo, PUC- São Paulo, 01 a 04 de outubro 2001. 
MANIN, B. As Metamorfoses do Governo Representativo. Revista Brasileira de Ciências Sociais, São Paulo, n. 29, ano 10, p. 5-34, out. 1995.

MCCOMBS, M. E.; Shaw, D. L. The agenda-setting function of mass media. Public opinion quaterly, Chicago, v. 36, n. 2, p. 176-187, summer 1972.

NOELLE-NEUMANN, E. Pesquisas eleitorais e clima de opinião. Opinião pública, Campinas, v. 1, n. 2, p.47-62, dez. 1993.

PINTO, C. R. J. Ao eleitor a verdade: o discurso político na imprensa em tempos de eleições. In: BAQUERO, M. (Org.). Brasil- transição, eleições e opinião pública. Porto Alegre: Editora da UFRGS, 1995. p. 67-78.

PORTO, M. Interpretando o mundo da política: perspectivas teóricas no estudo da relação entre psicologia, poder e televisão. XXIII ANPOCS, Caxambu (MG), Brasil, outubro de 1999.

REES, L. Vende-se política. Rio de Janeiro: Revan, 1995.

SAPERAS, E. Los efectos cognitivos de la comunicación de massas. Barcelona: Ed. Ariel, 1987.

SERRA, J. Pesquisismo. Folha de São Paulo, 18 out. 1994.

SILVA, K. B. da. A hora das verdades: personalismo e partidarismo no horário gratuito de propaganda eleitoral nas eleições para governador do Rio Grande do Sul em 2002. 2004. Dissertação (Mestrado em Ciência Política), Instituto de Filosofia e Ciências Humanas, UFRGS, [2004].

VEIGA, L. F. Propaganda Política e Voto: O Estudo do Efeito da Persuasão do Horário Eleitoral- Estado do Rio de Janeiro, em 1994, 20 Turno. 1996. 91 f. Dissertação (Mestrado em Ciência Política), IUPERJ, [1996].

Horário eleitoral, o eleitor e a formação da preferência. Trabalho apresentado no I Encontro da Associação Brasileira de Ciência Política- ABPC, Universidade Cândido Mendes, Rio de Janeiro, dez. 1998.

Em busca das razões para o voto: o uso que o eleitor faz da propaganda política. Contracampo: Revista do Mestrado em Comunicação, imagem e informação, Niterói, n. 7, p. 183-208, jul.-dez. 2002. 